\title{
Effect of the surgeonfish Ctenochaetus striatus (Acanthuridae) on the processes of sediment transport and deposition on a coral reef in the Red Sea
}

\author{
R. Krone $\cdot$ M. Paster $\cdot$ H. Schuhmacher \\ Received: 22 April 2010 / Accepted: 25 September 2010 \\ Springer-Verlag 2010
}

Facies DOI 10.1007/s10347-010-0239-8

\begin{abstract}
Excessive sedimentation is a major threat to coral reefs. It can damage or kill reef-building corals and can prevent the successful settlement of their planktonic larvae. The surgeonfish Ctenochaetus striatus feeds on rocky surfaces by sweeping loose material into its mouth with its flexible, broom-like teeth. In addition, it grasps and removes hard substrates with the aid of its special palate structure. It then transports sediment matter of the reef by defecating the ingested material outside the rocky zone of the reef. We analyzed 150 feces samples of six individuals, diferentiating between (1) ingested by sweeping and (2) ingested by scraping, and compared their content with inorganic land-derived and marine sediments trapped at the feeding area. Projections based on fish densities, defecation rates, and quantities as well as composition of sediments collected by traps on the same reef site suggest that $\boldsymbol{C}$. striatus removes at least $18 \%$ of the inorganic sediment sinking onto the reef crest. The eroded share in the exported matter is about $13 \%$. This finding points to a hitherto not verified role of $C$. striatus as a reef sweeper and reef scraper, whereby the first function is by far dominating.
\end{abstract}

Keywords Coral reefs, Red Sea, Sedimentation, Feeding and defecation behaviour, Reef sweeper 